\title{
Management of Urinary Tract Involvement in Placenta Accreta: A Single Institution Experience of 10 Cases
}

\author{
(1) Omar Salim Akhtar1, (1) Sabahat Rasool2, (1) Ufaque Muzaffar2, (1) Farhat Jabeen² \\ 1 Department of Urology, Government Medical College, Srinagar, Kashmir, India \\ 2Department of Obstetrics and Gynecology, Government Lal Ded Hospital, GMC, Srinagar, Kashmir, India
}

\section{What's known on the subject? and What does the study add?}

Placenta accreta is the adherence of placenta to surrounding organs beyond the uterus and occurs in about 1/500 pregnancies. It most commonly invades the urinary bladder. Rarely, ureteral and small bowel invasions are reported. In order to manage such cases, a multidisciplnary approach is required, involving obstetricians, urologists, interventional radiologists, and critical care physicians. Morbidity and mortality rates are high in placenta accreta. The management of 10 cases out of 80 cases (12.5\%) of placenta accreta which involved the urinary system is detailed. This is a relatively large number of cases of urinary tract involvement in any case series published thus far and adds to the epidemiological data of this disease. Multi-disciplinary approach is strongly recommended.

\section{Abstract}

Objective: Placenta accreta spectrum (PAS), which occurs in 1/500 deliveries, represents the disorders that arise due to adherent placenta, which may infiltrate adjacent organs, including the urinary tract. Recently, its incidence rate has increased because of increasing rate of cesarean deliveries worldwide.

Materials and Methods: Case records of all institutional deliveries that took place at a single, tertiary care hospital within two years were reviewed to identify all patients with PAS. The case records of patients who required urological referral were studied.

Results: In total, 80 patients were diagnosed with PAS. Ten patients (12.5\%) required urological referral for urinary tract involvement. All (100\%) patients showed bladder involvement. Two patients (2.5\%) required ureteric reimplantation. One patient (1.2\%) required bilateral ureterostomies as an urgent temporizing measure because the bladder was extensively infiltrated. All patients were discharged in a stable condition. There were no long-term urological complications observed in patients who followed up (90\%).

Conclusion: PAS is a condition with high mortality and morbidity rates and increasing incidence. The findings of this study correlate well with international series on PAS. A multidisciplinary management team is necessary to manage the myriad complications that may arise from PAS.

Keywords: Placenta accreta, placenta percreta, bladder injury

\section{Introduction}

In normal pregnancies, the placenta attaches to the superficial decidua of the endometrium and detaches easily after birth. Placenta accreta spectrum (PAS) is a condition wherein the placenta adheres to the endometrium (most common, 80\% of adherent placentae), myometrium (placenta increta, 15\% of cases), and other surrounding tissues [placenta percreta (PP), 5\% of cases] (1). The incidence rate of PAS is $\sim 1 / 533$ deliveries, and this has increased by $\sim 50$-fold in the last 70 years (2). The most involved secondary organ is the bladder (3), whereas ureteral and ileal invasions have been rarely reported $(3,4)$.

Urological complications arise from the direct infiltration of the bladder, which can be inseparable from the placenta, necessitating a cystotomy or partial cystectomy. Unilateral or bilateral ureters may also be involved or injured during surgery, necessitating a ureteric reimplantation (5).

Women with previous cesarean deliveries who underwent uterine procedures and had in vitro pregnancies are at the

Correspondence: Omar Salim Akhtar MD, Department of Urology, Government Medical College, Srinagar, Kashmir, India

E-mail: omarakhtar@hsshcc.org ORCID-ID: orcid.org/0000-0002-2316-6981

Received: 06.01.2021 Accepted: 23.02.2021

Cite this article as: Akhtar OS, Rasool S, Muzaffar U, Jabeen F. Management of Urinary Tract Involvement in Placenta Accreta: A Single Institution Experience of 10 Cases. J Urol Surg 2021;8(3):208-211.

${ }^{\circ}$ Copyright 2021 by the Association of Urological Surgery / Journal of Urological Surgery published by Galenos Publishing House. 
greatest risk of developing PP. The increasing rate of incidence has been attributed to the increasing incidence of cesarean sections and uterine procedures performed globally $(6,7)$.

Its pathophysiology is believed to be related to the invasion of weakened scar sites. Due to the potentially life-threatening hemorrhage, radical surgery with cesarean delivery, hysterectomy, and bladder reconstruction remain the mainstay of management (8).

This study aimed to highlight the experience of one referral institution in the management of PP that involves the urinary tract over the study period.

\section{Materials and Methods}

A retrospective review of all patients with PAS who were referred for a urological consult at the Government Lal Ded Hospital for Women, Srinagar, Kashmir, India, within the study period of June 2018-June 2020 was done. Previous obstetric history, presentations, timing of urological consultation, surgeries performed, transfusions required, outcomes of surgeries, and follow-up data were recorded. All patients underwent cesarean hysterectomy, and urological consultation was done in an emergency setting in all cases.

As the study formed a part of an audit, no institutional ethics approval was sought.

\section{Results}

In total, 80 patients with placenta accreta were identified. The incidence of placenta accreta during this study period was 2.23/1000 institutional deliveries. Of the 80 patients, one died $(1 / 80,1.25 \%)$. Hysterectomy was required in 53 patients
(53/80, 66.25\%). Nineteen (19/80, 23.75\%) patients required inotropic support and intensive care unit (ICU) care. Fifty-five patients $(55 / 80,68.75 \%)$ were electively managed, whereas the remaining $(25 / 80,31.25 \%)$ required emergency management. All cases were managed by the senior-most consultant gynecologist on duty (minimum of 5 years post-residency experience), and urological complications were managed by the urologist on duty (minimum of 5 years of post-residency experience).

Ten patients with PAS had urological complications requiring urological referral (Table 1). The average age of these patients was 32.7 years. Of these, four patients were para 1, five were para 2, and one was para 3. All had a history of previous cesarean section. Of these 10 patients, seven delivered in an elective setting, whereas three delivered in an emergency setting. The gestational age of three, three, and four patients was $<34$ weeks, $34^{0}-36^{+6}$ weeks, and $>37^{0}$ weeks, respectively. Nine of these 10 patients (90\%) were diagnosed antenatally. All antenatal diagnoses were done via ultrasound (USG). No patient underwent magnetic resonance imaging (MRI). No patient underwent any urological interventions, like ureteral stenting or cystoscopy, prior to surgery. No patient received any preoperative embolization, and no patient presented with hematuria. All the patients underwent hysterectomy.

Ten patients had PP that infiltrated the bladder. Seven of these patients were managed with partial cystectomy of the involved bladder wall. All cases required an indwelling Foley catheter to be placed for 3 weeks. In four cases, due to severe damage to the bladder wall, an additional suprapubic catheter (SPC) was placed. The SPC was removed 3 weeks after the surgery at the time of cystoscopy and on-table cystogram, which confirmed no visible leaks. The Foley catheters in the SPC cases were removed 1 week later to permit the healing of the SPC tract. In other cases, the Foley catheters were removed after 3 weeks after an

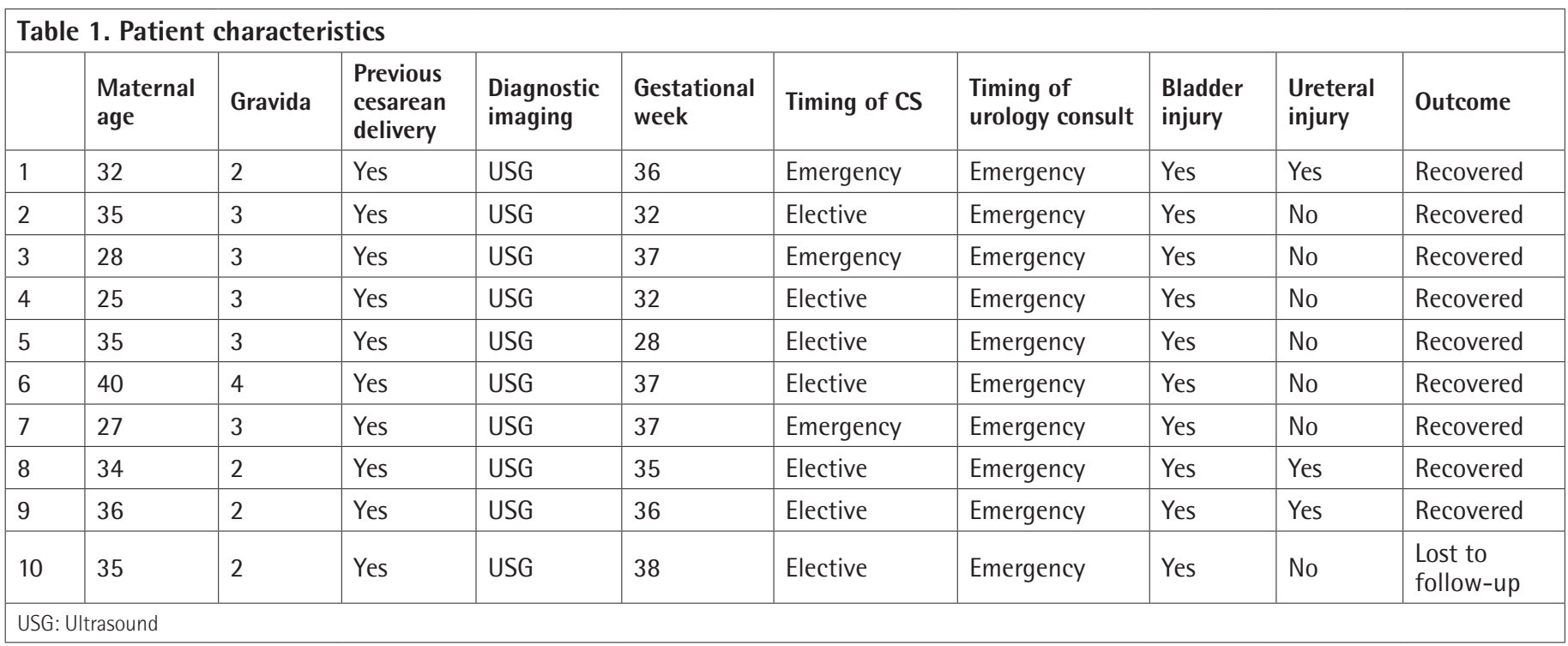


on-table cystogram that confirmed no visible contrast leaks.

Two patients required ureteric reimplantation on the anterolateral walls of the bladder using the Lich-Gregoir technique (extravesical ureteroneocystostomy). The reimplantation was done because of dense infiltrations in the posterior bladder wall in both cases. In both cases, the bladder infiltrations resulted in the need for bladder repair. The anastomosis on both sides was protected with Double-J (DJ) ureteric stents, which were left in situ for 6 weeks. A Foley catheter was left in situ for 3 weeks, which was removed after an on-table cystogram and absence of any visible contrast leaks. At the time of the removal of the DJ stents, serum creatinine levels were determined, and USG and kidney, ureter, and bladder X-ray were performed to confirm the position of the stents and the condition of the kidneys.

One patient had a severely infiltrated bladder, which precluded a ureteric reimplantation. In this case, bilateral ureterostomies were made in the anterior abdominal wall as a temporizing measure. This patient was discharged in a stable condition but was lost to follow-up.

No patient in this group required reinterventions for hemorrhage or urological complications. All patients in this group were managed postoperatively in the ICU before being shifted to a general ward. The patients were not discharged from the hospital until they were ambulatory and after being taught about catheter care. First, a urological follow-up was scheduled 3 weeks after the surgery. In this group, no patient died. One neonatal death occurred in this series.

A long-term urological follow-up (6 months postoperatively) was available in nine out of 10 cases, who were all urologically asymptomatic.

\section{Discussion}

$\mathrm{PP}$ can result in a massive maternal hemorrhage, severe urinary tract injuries, and maternal or neonatal death (2). In this case series, the incidence of urinary tract involvement requiring an intervention was $12.5 \%$ (10/80). In a review by Tam Tam et al. (9), the incidence of urinary tract involvement by PP was found to be $29 \%$ (83/292). In a series by Norris et al. (10), the incidence rate of PP that required urological reconstruction (cystotomy closure or reimplantation) was $28 \%(14 / 49)$. In a study of Nieto-Calvache et al. (11), the incidence of urinary tract injuries was 28\% (18/65); 15 patients had bladder injury secondary to involvement in PP, six had ureteral injury, and two had urinary tract fistula, which were both discovered postoperatively. In a series by Woldu et al. (12), cystotomy was done in $27 \%$ of cases (22/83), and ureteral injury was observed in $4 \%$ of cases (3/83).

A urological consultation was sought in an emergency setting in all cases. This is attributed to the relatively low incidence of urological involvement in placenta accreta observed in the study center. At the study center, the urologist was called after the delivery of the baby and for the completion of cesarean hysterectomy (in all cases in this series) and bleeding control.

Seven of the 10 patients required a partial cystectomy due to adherent and invasive PP into the bladder wall. The separation of the placenta from the bladder is not recommended as it can lead to torrential haemorrhage (3). Instead, the bladder wall was excised along with the placenta, creating a cystotomy and necessitating a partial cystectomy.

Two patients required bilateral ureteric reimplantation because of the involvement of the placenta at the posterior bladder wall. Bilateral ureteric reimplantation was done on the anterolateral wall of the bladder using the Lich-Gregoir method over a DJ polyurethane stent. In a series of Norris et al. (10), ureteric reimplantation was done in $8.1 \%$ (4/49) of cases with placenta accreta. Camuzcouglu et al. (13) reported a bladder injury rate of $6.9 \%(4 / 58)$, with no ureteral injury in all cases and no required ureteral reimplantation.

In one patient in this case series, the bladder was infiltrated extensively, which necessitated a bilateral ureterostomy as a temporizing measure. Upon reviewing literature, there was no mention of any case that required such an intervention. This patient was lost to follow-up after being discharged in a stable condition.

No patient in this series developed a urinary fistula. In a study by Nieto-Calvache, there were two reported urinary fistulae $(3 \%, 2 / 65)$, which were diagnosed after surgery $(11)$. In a series by Norris et al. (10), no patient developed a urinary fistula.

To the best of our knowledge, this is the first series published from the region. The limitations of this study include its small sample size and retrospective nature. The calculated incidence of PAS $(0.23 \%)$ is for the institutional deliveries at a single institution and is not representative of the entire population. In a study by Abbas et al. (3), the incidence of PAS was $0.9 \%$ at a single institution over a 12-year period.

A review by Al-Khan et al. (14) showed that an institution of team-based care resulted in improved outcomes of placenta accreta disorders. It may be worthwhile to develop a multidisciplinary team at all large, referral obstetric hospitals to manage such complex cases.

Urologists were called after the delivery of the baby, and hysterectomy was completed. No patient had preoperative ureteric stents placed. No patient underwent MRI.

Based on this study and literature review, it is recommended to avoid urological complications, and preoperative preparation is important. An MRI may be used to delineate the extent of 
placental invasion and to select patients who may require preoperative ureteral stenting. A multidisciplinary management team with anesthesiologists, gynecologists, urologists, general surgeons, and intensivists is recommended as intraoperative readiness cannot be overemphasized.

\section{Conclusion}

PP is a complicated condition that should be managed by a multidisciplinary team at a well-equipped center to handle all potential pitfalls. Antenatal diagnosis is mandatory and is required for a successful outcome. Urologists play an important role in preventing and treating its complications.

\section{Ethics}

Ethics Committee Approval: As the study formed a part of an audit, no institutional ethics approval was sought.

Informed Consent: The study is part of an audit.

Peer-review: Externally peer-reviewed.

\section{Authorship Contributions}

Surgical and Medical Practices: O.S.A., S.R., U.M., F.J., Concept: O.S.A., S.R., U.M., Design: O.S.A., F.J., Data Collection or Processing: O.S.A., S.R., U.M., Analysis or Interpretation: O.S.A., Literature Search: O.S.A., S.R., Writing: O.S.A.

Conflict of Interest: No conflict of interest was declared by the authors.

Financial Disclosure: The authors declare that they have no relevant financial.

\section{References}

1. Caliskan E, Tan O, Kurtaran V, Dilbaz B, Haberal A. Placenta previa percreta with urinary bladder and ureter invasion. Arch Gynecol Obstet 2003;268:343-344.
2. Wu $S$, Kocherginsky M, Hibbard JU. Abnormal placentation: twenty-year analysis. Am J Obstet Gynecol 2005;192:1458-1461.

3. Abbas F, Talati J, Wasti S, Akram S, Ghaffar S, Qureshi R. Placenta percreta with bladder invasion as a cause of life threatening hemorrhage. J Urol 2000;164:1270-1274.

4. Pearl ML, Escamilla G, Karpel BM, Kaplan C, Jones C, Westermann C. Conservative management of placenta percreta with involvement of the ileum. Arch Gynecol Obstet 1996;258:147-150.

5. Ng MK, Jack GS, Bolton DM, Lawrentschuk N. Placenta percreta with urinary tract involvement: the case for a multidisciplinary approach. Urology 2009;74:778-782.

6. Silver RM, Landon MB, Rouse DJ, Leveno KJ, Spong CY, Thom EA, Moawad AH, Caritis SN, Harper M, Wapner RJ, Sorokin Y, Miodovnik M, Carpenter M, Peaceman AM, O'Sullivan MJ, Sibai B, Langer O, Thorp JM, Ramin SM, Mercer BM; National Institute of Child Health and Human Development Maternal-Fetal Medicine Units Network. Maternal morbidity associated with multiple repeat cesarean deliveries. Obstet Gynecol 2006;107:12261232.

7. Fitzpatrick KE, Sellers $S$, Spark P, Kurinczuk JJ, Brocklehurst P, Knight M. Incidence and risk factors for placenta accreta/increta/percreta in the UK: a national case-control study. PLoS One 2012;7:e52893.

8. Washecka $R$, Behling A. Urologic complications of placenta percreta invading the urinary bladder: a case report and review of the literature. Hawaii Med J 2002;61:66-69.

9. Tam Tam KB, Dozier J, Martin JN Jr. Approaches to reduce urinary tract injury during management of placenta accreta, increta, and percreta: a systematic review. J Matern Fetal Neonatal Med 2012;25:329-334.

10. Norris BL, Everaerts W, Posma E, Murphy DG, Umstad MP, Costello AJ, Wrede $C D$, Kearsley J. The urologist's role in multidisciplinary management of placenta percreta. BJU Int 2016;117:961-965.

11. Nieto-Calvache AJ, López-Girón MC, Messa-Bryon A, Ceballos-Posada ML, Duque-Galán M, Ríos-Posada JG, Plazas-Córdoba LA, Chancy-Castaño MM. Urinary tract injuries during treatment of patients with morbidly adherent placenta. J Matern Fetal Neonatal Med 2021;34:3140-3146.

12. Woldu SL, Ordonez MA, Devine PC, Wright JD. Urologic considerations of placenta accreta: a contemporary tertiary care institutional experience. Urol Int 2014:93:74-79.

13. Camuzcuoglu A, Vural M, Hilali NG, Incebiyik $A$, Yuce HH, Kucuk $A$, Camuzcuoglu H. Surgical management of 58 patients with placenta praevia percreta. Wien Klin Wochenschr 2016;128:360-366

14. Al-Khan A, Gupta V, Illsley NP, Mannion C, Koenig C, Bogomol A, Alvarez M, Zamudio S. Maternal and fetal outcomes in placenta accreta after institution of team-managed care. Reprod Sci 2014;21:761-771. 